\title{
Utilizing blast furnace ferronickel slag as paste replacement to reduce white Portland cement content and improve performance of mortar
}

\author{
Qingfeng Guan ${ }^{1,2,3}$, Jingliang Xia ${ }^{1,2,3}$, Faguang Leng ${ }^{1,2,3}$ and Yongxiang Zhou ${ }^{1,2,3^{*}}$ (D)
}

* Correspondence:
xiangzizhou2006@126.com
${ }^{1}$ Institute of Building Materials,
China Academy of Building
Research, Beijing, China
${ }^{2}$ National Engineering Research
Center of Building Technology,
Beijing, China
Full list of author information is
available at the end of the article

available at the end of the article

\begin{abstract}
As a special type of cement that can provide construction with aesthetics, white Portland cement (WPC) is restricted by the high cost of its production. To reduce the consumption of WPC and carbon dioxide emissions without degrading the properties of mortar, this work produced various mortar mixes by replacing an equal volume of the paste (the total volume of WPC and water) with blast furnace ferronickel slag (FNS), the by-product of ferronickel smelting. The workability, 28-day compressive strength, carbonation depth, water permeability, and drying shrinkage test were conducted, and mercury intrusion porosimetry (MIP) test was used to characterize the pore structure. The results show that the paste replacement method is eco-friendlier and more effective than the traditional cement replacement technology in utilizing FNS to reduce WPC consumption, which may promote the development of white concrete construction.
\end{abstract}

Keywords: Blast furnace ferronickel slag, White Portland cement, Pore structure, Mechanical properties, Durability

\section{Introduction}

White Portland cement (WPC) is widely used in architectural concrete in applications such as prestige construction projects and decorative works because of its perfect white appearance and satisfactory performance similar to the ordinary Portland cement. However, producing WPC necessitates the careful selection of raw materials with a very low content of iron oxide and manganese oxide (Tziotziou et al., 2011; Zhang et al., 2019). Moreover, its production process can consume more energy, and the cement grains usually need to be ground into fine particles (Hamad, 1995). Hence, white Portland cement is relatively expensive and is utilized selectively in nonmechanical components (Júlio et al., 2006). In fact, in the production of ordinary concrete with gray cement, it is common to add the mineral admixture from industrial residues to reduce a portion of Portland cement and thus cut the construction costs while maintaining the mechanical performance and durability of the concrete (Balonis, 2019;

(c) The Author(s). 2021 Open Access This article is licensed under a Creative Commons Attribution 4.0 International License, which permits use, sharing, adaptation, distribution and reproduction in any medium or format, as long as you give appropriate credit to the original author(s) and the source, provide a link to the Creative Commons licence, and indicate if changes were made. The images or other third party material in this article are included in the article's Creative Commons licence, unless indicated otherwise in a credit line to the material. If material is not included in the article's Creative Commons licence and your intended use is not permitted by statutory regulation or exceeds the permitted use, you will need to obtain permission directly from the copyright holder. To view a copy of this licence, visit http://creativecommons.org/licenses/by/4.0/. 
Honglei et al., 2020; Jaafri et al., 2019; Nežerka et al., 2019; Shen et al., 2020a, b; Suleiman et al., 2019). In this context, mineral admixtures which can produce a white or whitish appearance and have pozzolanic activity can be exploited to replace part of WPC and promote the development of color concrete as well as the consumption of by-products.

In smelting industry, blast furnace ferronickel slag (FNS) is a type of granulated molten slag of nickel ore the nickel and iron of which are extracted in the blast furnace process before being quenched with water (Huang et al., 2017; Saha et al., 2018; Wang et al., 2018a, b). In general, the type of FNS which primarily consists of $\mathrm{SiO}_{2}, \mathrm{Al}_{2} \mathrm{O}_{3}$, and $\mathrm{CaO}$ contains a large proportion of an amorphous phase (Wang Dengquan et al., 2020; Wang Zhong Jie et al., 2010; Zhuang and Wang, 2021), which leads to its pozzolanic properties (Huang et al., 2017). According to the statistical data, approximately 12 to 14 tons of ferronickel slag may be generated just to produce 1 ton of nickel alloy (Saha and Sarker, 2016), so more than 30 million tons of ferronickel slag is discharged and accumulated in China every year (Peng et al., 2015). Such a by-product without effective utilization will pose a negative impact on the environment and will even limit the development of ferronickel industry. In this context, concrete industry with a remarkable capacity for waste consumption can undertake the task of reutilizing large quantities of blast furnace ferronickel slag (Cohen et al., 1993; Dhal et al., 2013; Park, 2013). At present, FNS is used to replace aggregate or cement in cementitious mortar or concrete.

When utilized as a substitute for aggregate, FNS is incorporated to reduce part of fine aggregate; moreover, it has been discovered that blast furnace ferronickel slag positively affects the mechanical properties and durability of cementitious mortar or concrete. In 2017, Saha and Saker (2017) found that replacing $50 \%$ or $100 \%$ of natural sand by granulated ferronickel slag could increase the strength of concrete significantly, and there was a limited amount (far below the regulatory limit) of heavy metal leaching out of the concrete. Saha et al. (2019) also exploited granulated ferronickel slag to replace 50\% of natural sand in concrete and revealed that the addition of granulated ferronickel slag could improve the dimensional stability and the compressive strength of the concrete but could slightly lower the residual strength of the concrete after being exposed to a temperature up to $600{ }^{\circ} \mathrm{C}$. In another work, Sun et al. (2019) used ferronickel slag to replace fine aggregate in concrete and found that the mechanical strength of the concrete and its resistance to the penetration of chloride ions could increase with the addition of ferronickel slag; it was also beneficial to the resistance of the concrete to fire and sulfate attack.

Blast furnace ferronickel slag can also be incorporated into concrete to replace different percentages of the cement binder. For example, Rahman et al. (2017) demonstrated that adding ground granulated ferronickel slag up to $50 \%$ in place of cement did not have a significant impact on setting time or water demand but decreased the 90-day compressive strength of the mortar. In another work, Huang et al. (2017) found that ferronickel slag powder could be substituted for a portion of cement with an increase in the resistance of the concrete to chloride ions and without a significant decrease in its strength. Moreover, Li et al. (2019a, b, c, d, e, f) investigated the resistance of cementitious mortar to sulfate ions when $20 \%$ of the cement was replaced by ferronickel 
slag and found that FNS could improve the resistance of cement mortar in early curing periods regardless of the curing conditions.

However, it should be noted that the methods for replacing both cement and aggregate with FNS have a certain drawback although they may be beneficial to environmental protection and waste utilization. In the cement replacement strategy, the mechanical properties of concrete significantly degenerate when an extremely high content of cement is replaced by FNS because its addition increases the factual water-tocement $(\mathrm{W} / \mathrm{C})$ ratio, thereby impairing the strength and compaction of cementitious materials (Choi and Choi, 2015; Saha and Sarker, 2016). In the aggregate replacement strategy, the carbon footprint of concrete production and cement consumption cannot be lowered because the content of cement remains constant (Katsiotis et al., 2015; Lemonis et al., 2015). Therefore, it is desirable to develop some advanced and more effective methods to improve the utilization rate of FNS, to reduce the cement consumption, and to limit carbon emissions while maintaining the strength, volume stability, and durability of mortar or concrete.

In recent years, some works (Kwan et al., 2013; Li et al., 2019c, 2019b, 2019a; Li et al., 2018b, 2018a; Li et al., 2018; Li et al., 2020; Ling and Kwan, 2016) have devised a novel technique, named the paste replacement method, to utilize solid waste for replacing an equal volume of cement paste, i.e., the total volume of cement and water. This replacement method can decrease the consumption of cement but does not change the ratio of water to cement, so the performance of concrete does not significantly decline. In our experimental study, the costly WPC was replaced with different volumes of the whitish FNS by means of the paste replacement method to produce some sets of mortar mixes with various water-to-cement ratios. The strength, water absorption rate, carbonation depth, and drying shrinkage strain of the concrete samples were investigated, and the pore structure of the paste samples was analyzed to understand the changing pattern of these properties.

\section{Materials and mix proportions}

\subsection{Preparation of materials}

A white Portland cement (WPC) composed of $53.29 \%$ of tricalcium silicate $\left(\mathrm{C}_{3} \mathrm{~S}\right)$, $29.92 \%$ of dicalcium silicate $\left(C_{2} S\right), 3.76 \%$ of tricalcium aluminate $\left(C_{3} A\right), 0.38 \%$ of tetracalcium aluminoferrite $\left(\mathrm{C}_{4} \mathrm{AF}\right)$, and $8.8 \%$ of calcite was used herein to produce the white cement mortar. Its chemical components determined by X-ray fluorescence spectrometer (XRF) mainly consist of $\mathrm{CaO}(72.27 \%), \mathrm{SiO}_{2}(18.77 \%)$, and $\mathrm{Al}_{2} \mathrm{O}_{3}(3.98 \%)$, as tabulated in Table 1 , and its Blaine fineness value and specific gravity are $334 \mathrm{~m}^{2} / \mathrm{kg}$ and 3.077 respectively. The natural sand with a moisture content of $0.13 \%$, water absorption of $0.91 \%$, a specific gravity of 2.665 , and a maximum particle size of $1.18 \mathrm{~mm}$ was selected as the fine aggregate.

Table 1 The chemical compositions of the white Portland cement and the blast furnace ferronickel slag

\begin{tabular}{lllllllllll}
\hline Oxide & $\mathbf{C a O}$ & $\mathbf{A l}_{2} \mathbf{O}_{\mathbf{3}}$ & $\mathbf{S i O}_{\mathbf{2}}$ & $\mathbf{S O}_{\mathbf{3}}$ & $\mathrm{Fe}_{\mathbf{2}} \mathbf{O}_{\mathbf{3}}$ & $\mathbf{K}_{\mathbf{2}} \mathbf{O}$ & $\mathbf{N a}_{\mathbf{2}} \mathbf{O}$ & $\mathbf{M g O}$ & $\mathbf{C r}$ & $\mathbf{L O I}$ \\
\hline White Portland cement (WPC) (wt\%) & 69.96 & 3.85 & 18.17 & 3.61 & 0.20 & 0.42 & 0.06 & 0.20 & - & 3.37 \\
Blast furnace ferronickel slag (FNS) (wt\%) & 31.73 & 20.92 & 26.85 & 4.14 & 1.26 & 0.24 & 0.70 & 9.2 & 1.34 & 0.32 \\
\hline
\end{tabular}


According to the scanning electron microscopy (SEM; MAIA3LMU, Czech) images (see Fig. 1), the blast furnace ferronickel slag used herein is a dry ground powder of the iron-extracted waste from Fujian province in China which is first quenched with water and then dried; it has a specific gravity, a maximum particle size, and a Blaine fineness value of $2.855,0.15 \mathrm{~mm}$, and $384 \mathrm{~m}^{2} / \mathrm{kg}$ respectively. The particle size distribution (PSD) of the WPC and the FNS were measured by a laser particle size analyzer, as depicted in Fig. 2, and the PSD of the fine aggregate was determined through mechanical sieving measurement. A continuous graded particle size distribution can be found for both the white cement and the FNS. The testing results of the autoclave method for soundness according to Chinese Standard GB/T 750 showed that the expansion of the FNS is $0.04 \%$ (less than $0.05 \%$ ), indicating that the content of $\mathrm{MgO}$ will not cause poor soundness in the mortar.

A polycarboxylate-based superplasticizer (SP) in the form of a white powder was used in the preparation of the mortar samples to maintain their constant workability.

\subsection{Mix proportions}

By varying the volume of the FNS added as a replacement for the paste, a series of water-to-cement ratios and various mortar mixes were designed for the experimentation. Firstly, the water-to-cement ratio $(\mathrm{W} / \mathrm{C})$ was set at $0.40,0.45,0.50$, and 0.55 by weight. As given in Table 2, the total volume of the paste of all the mortars, that is, the total volume of the WPC, the FNS, and water as a percentage of the mortar volume, was maintained at $60 \%$, and the volume of the fine aggregate was fixed at $40 \%$ by volume. To keep the total volume of the cementitious paste constant, the volume of the cement paste, i.e., the volume of the WPC and water, calculated as a percentage of the total volume of the mortar, was decreased by the addition of the FNS; the volume of the FNS was expressed in a percentage of the total volume of the white mortar. More precisely, the volume of the FNS was set at $0 \%, 5 \%, 10 \%, 15 \%$, and $20 \%$, and the corresponding volume of the cement paste was $60 \%, 55 \%, 50 \%, 45 \%$, and $40 \%$. Then, the dosage of the superplasticizer, that is, the mass of the solid superplasticizer expressed in a percentage of the total mass of the white cement and the FNS, was not prefixed

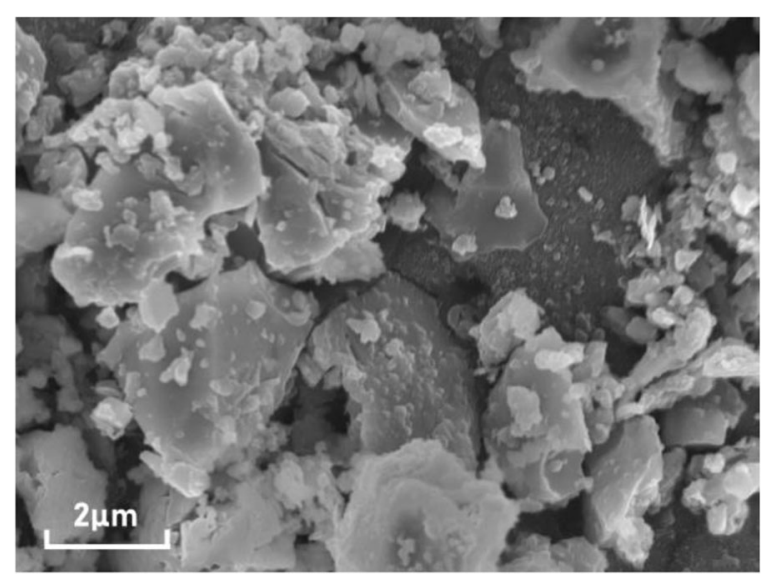

Fig. 1 The SEM image of the blast furnace ferronickel slag 


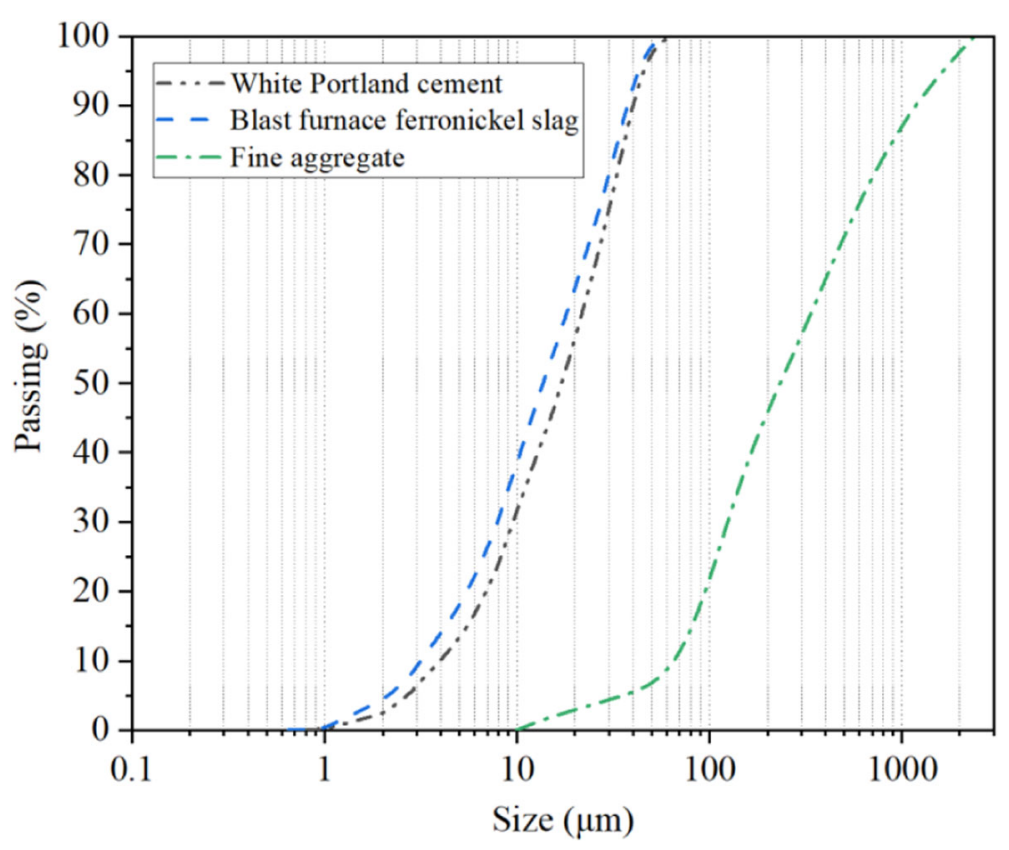

Fig. 2 The particle size distributions of the white Portland cement, the blast furnace ferronickel slag, and the fine aggregate

since the superplasticizer needed to be added little by little to the experimental samples to achieve a flow expansion in the range of 180 to $350 \mathrm{~mm}$.

Further, this work also planned to compare the difference between using the FNS as a substitute for the cement and as a substitute for the mortar paste by producing another six mortar samples. Similarly, the total volume fraction of the paste of each mix proportion was $60 \%$, and the volume of the FNS was increased from $0 \%$ to $20 \%$ with increments of $5 \%$ while the corresponding volume of the cement was decreased from $60 \%$ to $40 \%$ with decrements of $5 \%$. It should be emphasized that the incorporation of the FNS added as a replacement for the cement did not change the volume of water. In the cement replacement method, only the water-to-cement ratios of 0.40 and 0.55 were considered.

\section{Characterization}

\subsection{Slump flow test}

Similar to the slump test of concrete (Lavado J. et al., 2020; Li et al., 2021c), this study used a small-sized slump cone test for the mortar (Jiménez-Quero et al., 2013; Li et al., 2021b) to measure the slump flow of each mortar mix listed in Table 2. Having been filled up with the fresh mortar, the mini slump cone was lifted vertically, and then the mortar slumped and flew in a patty shape. Finally, the mean diameter of the patty in two orthometric directions was taken as the slump flow of the mortar mix.

\subsection{Measurement of compressive strength of mortar}

According to Chinese standard JGJ/T70-2009 (2009), the fresh mortar mix was cast into three cube specimens with the dimensions $100 \mathrm{~mm} \times 100 \mathrm{~mm} \times 100 \mathrm{~mm}$ and cured 
Table 2 The mix proportions of the white mortar mix

\begin{tabular}{|c|c|c|c|c|c|c|}
\hline Sample ID & Water $\left(\mathrm{kg} / \mathrm{m}^{3}\right)$ & $\begin{array}{l}\text { WPC } \\
\left(\mathrm{kg} / \mathrm{m}^{3}\right)\end{array}$ & $\begin{array}{l}\text { FNS } \\
\left(\mathrm{kg} / \mathrm{m}^{3}\right)\end{array}$ & $\begin{array}{l}\text { Fine aggregate } \\
\left(\mathrm{kg} / \mathrm{m}^{3}\right)\end{array}$ & $\begin{array}{l}\text { SP dosage (wt } \% \\
\text { of the cement) }\end{array}$ & $\begin{array}{l}\text { Rate of decrease in } \\
\text { white cement (\%) }\end{array}$ \\
\hline PRB-0.40-0 & 331 & 828 & 0 & 1032 & 0.04 & 0.00 \\
\hline PRB-0.40-5 & 303 & 759 & 150 & 1032 & 0.08 & 8.33 \\
\hline PRB-0.40-10 & 276 & 690 & 300 & 1032 & 0.12 & 16.67 \\
\hline PRB-0.40-15 & 248 & 621 & 451 & 1032 & 0.23 & 25.00 \\
\hline PRB-0.40-20 & 221 & 552 & 601 & 1032 & 0.37 & 33.33 \\
\hline PRB-0.45-0 & 348 & 774 & 0 & 1032 & 0.04 & 0.00 \\
\hline PRB-0.45-5 & 319 & 710 & 150 & 1032 & 0.06 & 8.33 \\
\hline PRB-0.45-10 & 290 & 645 & 300 & 1032 & 0.10 & 16.67 \\
\hline PRB-0.45-15 & 261 & 581 & 451 & 1032 & 0.18 & 25.00 \\
\hline PRB-0.45-20 & 232 & 516 & 601 & 1032 & 0.32 & 33.33 \\
\hline PRB-0.50-0 & 364 & 727 & 0 & 1032 & 0.03 & 0.00 \\
\hline PRB-0.50-5 & 333 & 667 & 150 & 1032 & 0.04 & 8.33 \\
\hline PRB-0.50-10 & 303 & 606 & 300 & 1032 & 0.09 & 16.67 \\
\hline PRB-0.50-15 & 273 & 545 & 451 & 1032 & 0.17 & 25.00 \\
\hline PRB-0.50-20 & 242 & 485 & 601 & 1032 & 0.28 & 33.33 \\
\hline PRB-0.55-0 & 377 & 686 & 0 & 1032 & 0.00 & 0.00 \\
\hline PRB-0.55-5 & 346 & 629 & 150 & 1032 & 0.03 & 8.33 \\
\hline PRB-0.55-10 & 314 & 571 & 300 & 1032 & 0.07 & 16.67 \\
\hline PRB-0.55-15 & 283 & 514 & 451 & 1032 & 0.14 & 25.00 \\
\hline PRB-0.55-20 & 251 & 457 & 601 & 1032 & 0.23 & 33.33 \\
\hline CRB-0.40-5 & 331 & 788 & 40 & 1032 & 0.05 & 0.05 \\
\hline CRB-0.40-10 & 331 & 747 & 81 & 1032 & 0.05 & 0.10 \\
\hline CRB-0.40-15 & 331 & 706 & 122 & 1032 & 0.05 & 0.15 \\
\hline CRB-0.40-20 & 331 & 666 & 162 & 1032 & 0.06 & 0.20 \\
\hline CRB-0.55-5 & 377 & 653 & 33 & 1032 & 0.00 & 0.05 \\
\hline CRB-0.55-10 & 377 & 619 & 67 & 1032 & 0.00 & 0.10 \\
\hline CRB-0.55-15 & 377 & 585 & 101 & 1032 & 0.00 & 0.15 \\
\hline CRB-0.55-20 & 377 & 552 & 134 & 1032 & 0.00 & 0.20 \\
\hline
\end{tabular}

in a standard curing room at a temperature of $23 \pm 2{ }^{\circ} \mathrm{C}$ and relative humidity of higher than $90 \%$ after the mini slump cone test. At a curing period of 28 days, the compressive strength of the specimens was measured by using a compression machine.

\subsection{Measurement of resistance of mortar to carbonation}

Complying with Chinese standard GB/T 50082-2009 (2009), the carbonation test was conducted to determine the resistance of the white mortar containing the FNS to carbonation. To this end, the prism specimens with the dimensions $100 \mathrm{~mm} \times 100 \mathrm{~mm} \times$ $300 \mathrm{~mm}$ were cast and cured in the standard curing room. After 26 days of curing, the specimens were removed from the curing room and dried at a temperature of $60 \pm 2{ }^{\circ} \mathrm{C}$ for 2 days. After being cooled down to room temperature, each dried specimen was coated with paraffin on all side surfaces except for one end surface with the dimensions $100 \mathrm{~mm} \times 100 \mathrm{~mm}$ and transferred into a carbonation machine. The temperature, 
relative humidity, and the concentration of carbon dioxide of the carbonation machine were set at $20 \pm 2{ }^{\circ} \mathrm{C}, 70 \pm 5 \%$, and $20 \pm 3 \%$ respectively. When the test arrived at 28 days, each mortar specimen was cut into two halves, and both the cut surfaces were sprayed with a $1 \%$ phenolphthalein solution. The resistance of the mortar mix to carbonation was determined by the mean distance from the contour of the cut surface to the boundary of the pink part.

\subsection{Measurement of water absorption of mortar}

The water absorption of the mortar specimens was measured using standard ASTM C1585-13 (2013). In this method, each mortar sample was cast into three cylindrical specimens with a height of $50 \mathrm{~mm}$ and a diameter of $100 \mathrm{~mm}$ and cured in the standard curing room for 28 days. Then, the mortars were first kept into a curing chamber at a temperature of $50 \pm 2{ }^{\circ} \mathrm{C}$ and relative humidity of $80 \pm 3 \%$ for 3 days and then maintained at a temperature of $23 \pm 2{ }^{\circ} \mathrm{C}$ for 15 days. Next, paraffin was used to coat the side surfaces of each mortar mix, and a loosely attached plastic film was employed to seal the surface of the one end of the cylinder specimen. At the beginning of the trial, the surface of the other end of the cylindrical specimen without any coating was placed into a water pond, and the amount of water absorption $(I)$ was calculated by the increase in the weight of the sample at different times $\left(m_{t}\right)$.

According to standard ASTM C1585-13 (2013) the water absorption at time $t$ is calculated as $I=\left(m_{t} / \rho_{w}\right) / A$ where $\rho_{w}$ is the density of water and $A$ represents the unsealed surface area of the sample. Some previous researches (Li et al., 2018b, 2018a) have reported that $m_{t}$ changes as a function of the square root of $t$, so the slope of the line of $I$ plotted against $t^{1 / 2}$ is defined as the absorption rate herein. Furthermore, all the data scattered over a range of $60 \mathrm{~s}$ to $6 \mathrm{~h}$ were used for the linear regression analysis, and the results determined the initial water absorption rate (IWAR) of the mortar. Meanwhile, the second water absorption rate (SWAR) of the mortar was calculated by the results of linear regression analysis based on all the data scattered over a range of $24 \mathrm{~h}$ to 8 days. Finally, the average water absorption rate of the mortar was calculated as the mean value of the water absorption percentages of three mortar samples.

\subsection{Measurement of drying shrinkage strain on mortar}

The shrinkage of each specimen was determined by the method developed by the research group of Li et al. (2011). Before casting the fresh mortar mix into three plastic molds with the dimensions $40 \mathrm{~mm} \times 40 \mathrm{~mm} \times 160 \mathrm{~mm}$, a hemispherical brass button was placed into a hole punched in the center of the surface of each end of the mold. After the mortar sample was cured in the standard curing room for 7 days, the surface of the two ends and the surface of the top and bottom of each mortar sample were sealed with paraffin; thus, the internal water or moisture of the mortar specimens could only escape through the two sides of the sample during the drying period. Before the formal test of the drying shrinkage, the distance between the two buttons of each specimen defined as the initial length $\left(L_{0}\right)$ was measured by a micrometer caliper with accuracy of $\pm 0.002 \mathrm{~mm}$. Subsequently, the specimens were kept in a curing maintainer at a temperature of $23 \pm 2{ }^{\circ} \mathrm{C}$ and relative humidity of $75 \pm 5 \%$ during the drying period. Since the shrinkage was relatively significant in early curing periods, the distance 
between the two buttons of each specimen at time $t\left(L_{t}\right)$ was recorded once a day during the first 30 days, then every 3 days during the second 30 days, and finally every 1 week during the third 30 days. The drying shrinkage strain on the mortar was calculated as $\left(L_{0}-L_{t}\right) / L_{0}$.

\subsection{Measurement of pore structure of mortar}

To clarify the influence of the pore structure of the mortar specimens, this study produced cementitious pastes without the fine aggregate using the mortar mix listed in Table 2. Each cementitious paste was prepared as prism samples with the dimensions $40 \mathrm{~mm} \times 40 \mathrm{~mm} \times 160 \mathrm{~mm}$ and then placed in a standard curing room at a temperature of $23 \pm 2{ }^{\circ} \mathrm{C}$ and relative humidity of higher than $90 \%$. At a curing period of 28 days, each prism sample was cut into slices with a thickness of $2-4 \mathrm{~mm}$, and these slices were then soaked in anhydrous ethanol for at least 5 days to stop the hydration process; the ethanol was changed when the sample soaked for $24 \mathrm{~h}$. Lastly, all the slices were removed from the solvent and then transferred to a vacuum drying chamber at a temperature of $40^{\circ} \mathrm{C}$ for at least 7 days to remove the residual ethanol. Mercury intrusion porosimetry (MIP, PoreMaster 33/60) was utilized to analyze the pore structure of the cement pastes.

\section{Results and discussion}

\subsection{Workability of mortar paste}

The dosage of the superplasticizer of each mix proportion required to obtain the expected workability is presented in Table 2 , and the factual slump flows of all the specimens are presented in the first column of Table 3.

Table 2 shows that the dosage of the superplasticizer at a similar W/C increased as the FNS was added as a replacement for the paste. For example, at a W/C of 0.40, the dosage of the superplasticizer increased from $0.04 \%$ to $0.37 \%$ as the addition of the FNS grew up to $20 \%$; however, at a W/C of 0.55 , the dosage of the superplasticizer rose from $0 \%$ to $0.23 \%$ as the volume of the FNS increased up to $20 \%$. As presented in Table 2, the FNS was added to the mortar mix to replace the equal volume of the white Portland cement and water; thus, when the volume of the FNS increased, the volume of water decreased, while the volume percentage of the powder (the white Portland cement and the FNS) increased. The water-to-powder ratio also declined constantly, indicating that the mortar mix was drier and required higher dosages of the superplasticizer to obtain the expected slump flow.

In addition, the actual slump flows measured ranged from 195 to $345 \mathrm{~mm}$, that is, there was a slight fluctuation in the data on the slump flow owing to the one-shot incorporation of the superplasticizer when mixing the fresh mortar. All the data listed in the second column of Table 3 varied in the range of 180 to $350 \mathrm{~mm}$, which fulfilled the requirements of mortar workability.

\subsection{Compressive strength of mortar}

The compressive strength of the concrete samples cured for 28 days under the standard curing conditions are depicted in Fig. 3. The data presented in this figure are the mean value of the compressive strength of the three specimens produced from the same 
Table 3 The experimental results of the mortar specimens

\begin{tabular}{lllll}
\hline Sample ID & Slump flow $(\mathbf{m m})$ & $\begin{array}{l}\text { Carbonation } \\
\text { depth }(\mathbf{m m})\end{array}$ & $\begin{array}{l}\text { Initial water absorption } \\
\text { rate }\left(1 \mathbf{1 0}^{-\mathbf{4}} \mathbf{m} / \mathbf{s}^{\mathbf{1 / 2}}\right)\end{array}$ & $\begin{array}{l}\text { Second water absorption } \\
\text { rate }\left(\mathbf{1 0}^{-\mathbf{4}} \mathbf{m m} / \mathbf{s}^{\mathbf{1 / 2}}\right)\end{array}$ \\
\hline PRB-0.40-0 & 210 & 2.1 & 49.6 & 10.6 \\
PRB-0.40-5 & 210 & 2.0 & 27.0 & 4.4 \\
PRB-0.40-10 & 195 & 1.9 & 25.2 & 2.1 \\
PRB-0.40-15 & 330 & 1.7 & 9.9 & 1.9 \\
PRB-0.40-20 & 280 & 1.7 & 6.5 & 1.4 \\
PRB-0.45-0 & 200 & 4.2 & 62.5 & 15.4 \\
PRB-0.45-5 & 190 & 3.7 & 33.8 & 4.9 \\
PRB-0.45-10 & 195 & 3.6 & 22.7 & 2.8 \\
PRB-0.45-15 & 345 & 3.4 & 6.9 & 1.7 \\
PRB-0.45-20 & 315 & 3.3 & 5.5 & 1.3 \\
PRB-0.50-0 & 265 & 5.4 & 103.0 & 27.2 \\
PRB-0.50-5 & 210 & 4.5 & 62.3 & 13.4 \\
PRB-0.50-10 & 220 & 4.4 & 24.4 & 2.9 \\
PRB-0.50-15 & 335 & 4.2 & 11.5 & 2.4 \\
PRB-0.50-20 & 302 & 3.8 & 6.6 & 1.9 \\
PRB-0.55-0 & 240 & 7.9 & 97.0 & 36.7 \\
PRB-0.55-5 & 210 & 6.6 & 49.1 & 17.7 \\
PRB-0.55-10 & 260 & 5.5 & 25.1 & 3.2 \\
PRB-0.55-15 & 325 & 5.4 & 10.5 & 2.9 \\
PRB-0.55-20 & 335 & 4.8 & 6.5 & 2.2 \\
\hline & & & & \\
\hline
\end{tabular}

concrete specimen and analyzed simultaneously. Meanwhile, the error bar of each mortar specimen is plotted in Fig. 3 to describe the fluctuation in the data on 28-day compressive strength of the concrete samples.

At a fixed $\mathrm{W} / \mathrm{C}$, the compressive strength of the "PRB" samples increased as a higher volume of the FNS was added to replace the paste, indicating that the addition of the FNS did not reduce the mechanical performance of the mortar. When the FNS was

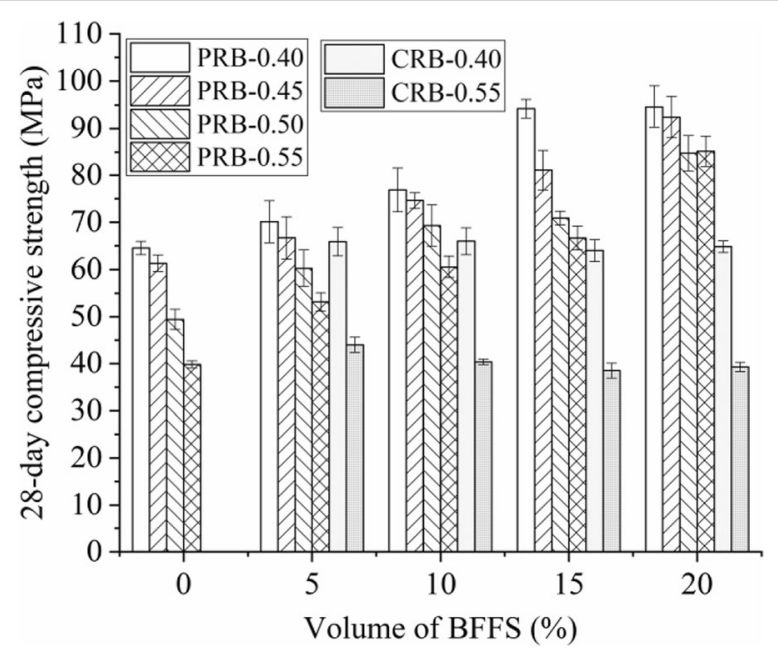

Fig. 3 The compressive strength of the mortar mix cured for 28 days 
used to replace the WPC by the cement replacement method, the compressive strength of the mortar could only remain at the initial level. For example, when the volume of the added FNS was $0 \%, 5 \%, 10 \%, 15 \%$, and $20 \%$, the compressive strength of sample CRB-0.40 was 64.5, 65.9, 66.0, 64.0, and $64.8 \mathrm{MPa}$ respectively. Hence, adding the FNS to replace the cement and water simultaneously is more effective in enhancing the strength of the mortar samples, which is consistent with the conclusions of previous works (Chen et al., 2014; Li et al., 2019c).

\subsection{Resistance of mortar to carbonation}

The resistance of concrete to carbonation plays a crucial role in the service life of steel bars in concrete structures. When concrete has a strong resistance to carbonation, the pore solution can have a high alkaline environment, and the passive film on the surface of rebars will not be destroyed.

The third column of Table 3 lists the testing results of the carbonation depth of the mortar mix. The addition of the FNS as a replacement for the paste decreased the carbonation depth of the mortar at a fixed W/C. For example, at a W/C of 0.40 , the carbonation depth of the mortar decreased from 2.1 to $1.7 \mathrm{~mm}$ as the volume of the FNS increased to $20 \%$. Furthermore, when the W/C decreased gradually, the carbonation depth of the sample correspondingly decreased which was reasonable since the mortar with a lower W/C generally had a stronger resistance to carbonation.

To further reveal the development of the resistance of the mortar mix to carbonation at various volumes of the FNS and different water-to-cement ratios, Fig. 4 describes the rate of decrease in the carbonation depth of the samples because of the incorporation of the FNS into the mortar as a replacement for the paste. At any W/C designed herein, the rate of decrease in the carbonation depth of the mortar continued increasing when the volume of the FNS rose from $0 \%$ to $20 \%$. This demonstrates that the strategy of adding the FNS as a replacement for the paste can improve the resistance of the mortar mixes to carbonation. Previous researches (L.G. Li et al., 2019; Li et al., 2021a) reported that the utilization of solid waste as a substitute for the paste could also enhance the resistance of mortar to carbonation. Nguyen et al. (2019) showed that the addition of ferronickel slag enhanced the resistance of the concrete samples to carbonation.

\subsection{Water absorption of mortar}

The fourth and fifth columns of Table 3 present the testing results of the initial water absorption rate and the second water absorption rate of the mortars. From the last two columns in Table 3, we infer that decreasing the W/C at the same volume of the FNS could reduce both the initial and second water absorption rates of the mortar since a lower water-to-cement ratio could usually improve the resistance of the mortar mix to water.

Another point worth emphasizing is that the IWAR and SWAR of the mortar were generally lower at a higher volume of the FNS and at a fixed W/C. For instance, at a W/C of 0.40 , the IWAR of the mortar declined from $49.6 \times 10^{-4}$ to $6.5 \times 10^{-4} \mathrm{~mm} / \mathrm{s}^{1 / 2}$, and the SWAR of the mortar decreased from $10.6 \times 10^{-4}$ to $1.4 \times 10^{-4} \mathrm{~mm} / \mathrm{s}^{1 / 2}$ as the volume of the FNS accumulated up to $20 \%$. 


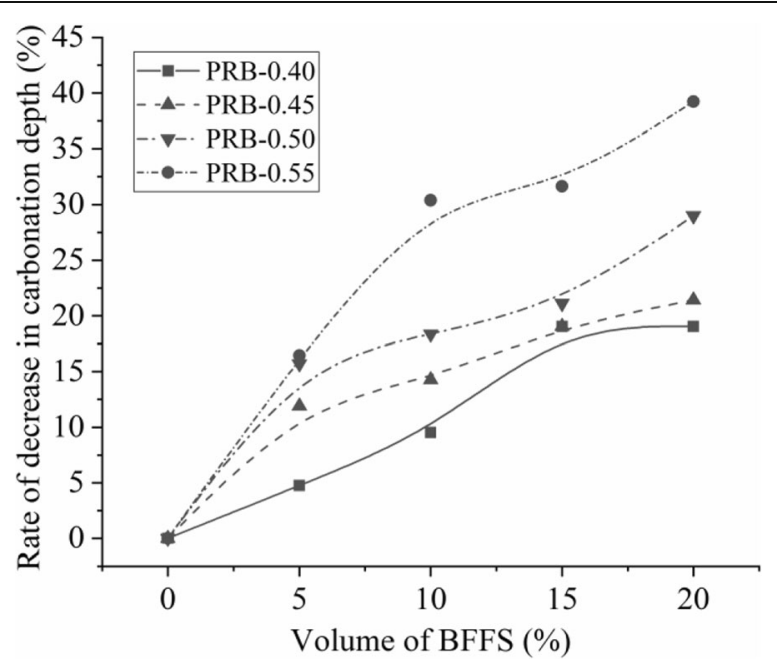

Fig. 4 The rate of decrease in carbonation depth of the PRB mortar versus the volume of the FNS at various water-to-cement ratios

To further detail the development of the resistance of the mortar mix to water at various volumes of the FNS and different water-to-cement ratios, Fig. 5 and Fig. 6 illustrate the percentage of the reduction in the IWAR and SWAR of the mortar when the FNS was added as a replacement for the paste. We can infer that, at any W/C designed in this experiment, the percentage of the reduction in the IWAR and SWAR continued increasing when the volume of the FNS increased from $0 \%$ to $20 \%$. When the volume of the FNS was $20 \%$, the IWAR and SWAR of the mortar specimens were $86.9 \%$ and $87.3 \%$ respectively at a $\mathrm{W} / \mathrm{C}$ of 0.40 . The changing patterns demonstrated that the strategy of adding the FNS as a replacement for the paste could reduce the water permeability of the cement mortar. Other works also reported similar improvement in the resistance of mortar to water absorption. For example, Chen et al. (2014) reported that the cement paste replacement could reduce the water absorption rate of concrete, and You et al. (2019) found that, compared to normal Portland concrete mortar, the testing mortar containing ferronickel slag had lower water permeability.

For various water-to-cement ratios, Fig. 5 reveals that the rate of decrease in the IWAR of the concrete samples at a W/C of 0.50 and 0.55 was higher than that a W/C of 0.40 and 0.45 respectively. Meanwhile, a W/C of 0.40 led to the lowest rate of decrease in the IWAR of the mortar as the volume of the FNS increased from $5 \%$ to $20 \%$. A similar pattern was also observed for the SWAR of the mortar samples, as shown in Fig. 6. It is obvious that a lower W/C could result in mortars with a higher compactness and a lower absorption rate. Mortar specimens with a higher $\mathrm{W} / \mathrm{C}$, such as 0.55 , had relatively lower compactness and would absorb more water, so the improvement in the water absorption rate of the samples due to the addition of the FNS as a substitute for the paste was more significant. Moreover, a $10 \%$ addition of the FNS appeared to be a critical percentage for the SWAR of the mortar since the rate of decrease in the SWAR was transformed into a gradually changing phase with the increase in the volume of the FNS, implying that further increasing the volume of the FNS would not obviously reduce the SWAR of the mortar samples. 


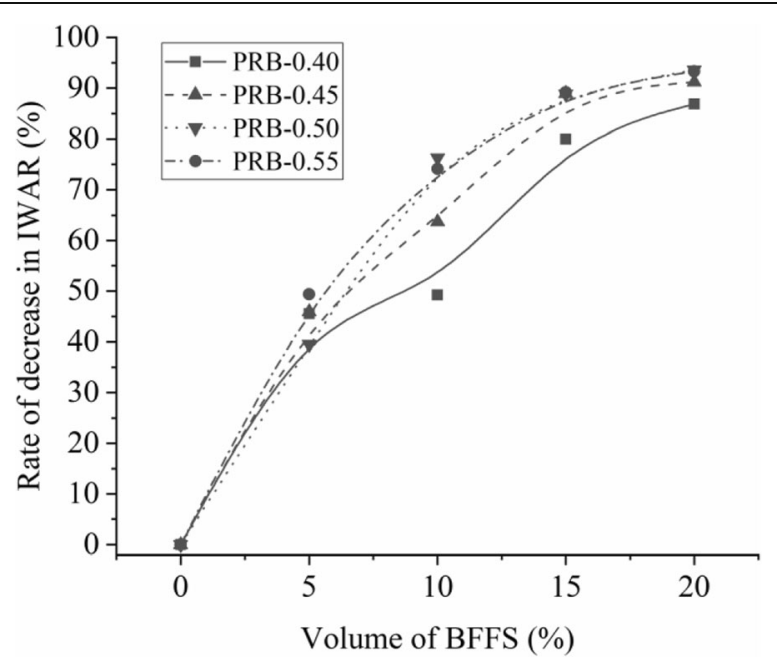

Fig. 5 The rate of decrease in the initial water absorption rate of the mortar versus the volume of the FNS at various water-to-cement ratios

\section{5 . Drying shrinkage strain on mortar}

The curves plotted in Fig. 7 describe the overall development of the drying shrinkage strain on the mortar specimens with various volumes of the FNS added as a replacement for the paste at a $\mathrm{W} / \mathrm{C}$ of 0.40 during the drying shrinkage measurement. An expected characteristic in the figure is that at a designed $\mathrm{W} / \mathrm{C}$, the mortar specimen exhibited a rapid increase in the drying shrinkage strain at an early curing period (in the first 30 days), and then shifted to present moderate development of the drying shrinkage strain approximately from day 30 to day 90 . It is noteworthy that the shrinkage curve showed a downward trend as the volume of the FNS increased, indicating that the drying shrinkage strain on the mortar mix could be restricted by the incorporation of the FNS into the mortar as a substitute for the paste.

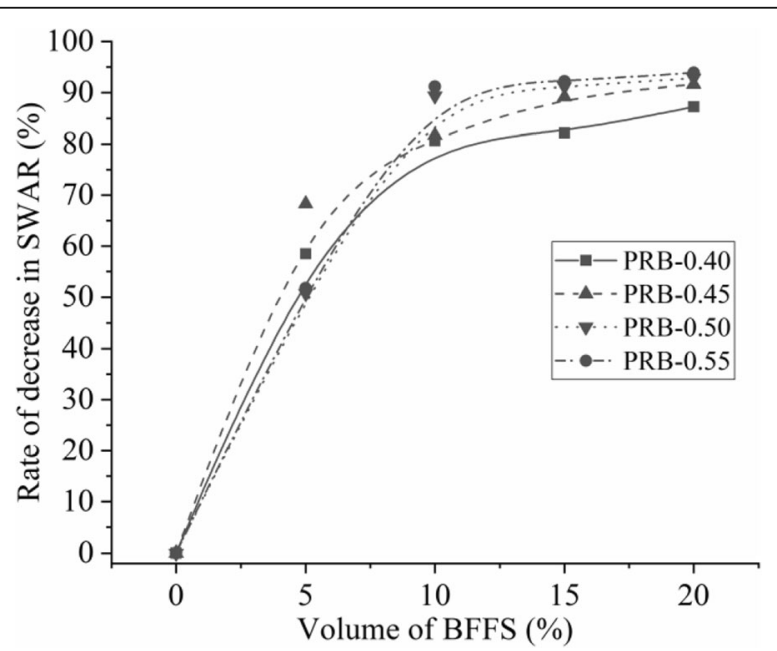

Fig. 6 The rate of decrease in the second water absorption rate of the mortar versus the volume of the FNS at various water-to-cement ratios 


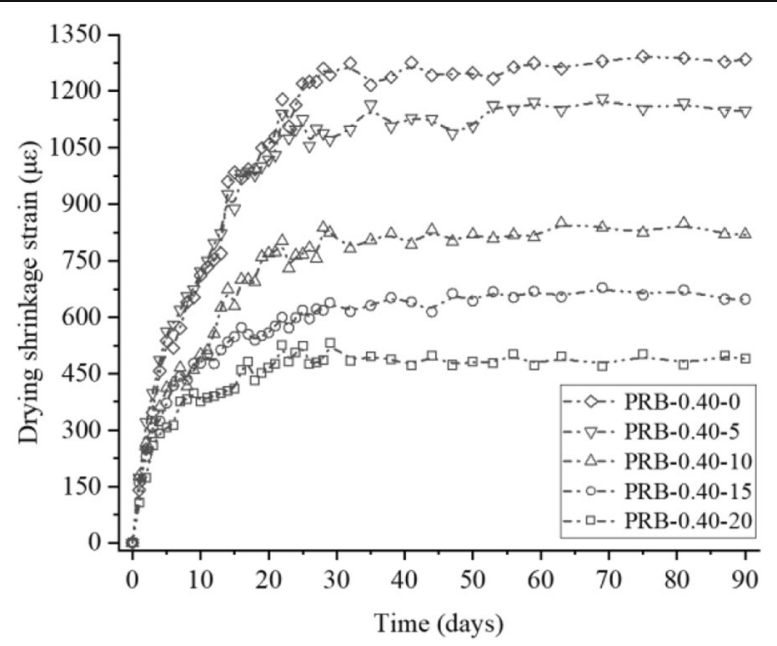

Fig. 7 The drying shrinkage strain on mortar sample PRB-0.40 at various volumes of the FNS

Furthermore, the ultimate shrinkage strain (USS) on the mortar was calculated as the drying shrinkage strain on the mortar specimens on day 90 because when the curing period reached 90 days, the development of the drying shrinkage strain on the mortar almost stopped and remained at a stabilized level for a long period. The USS on the mortars with different volumes of the FNS at various water-to-cement ratios is illustrated in Fig. 8 along with the error bars. As excepted (Maltese et al., 2005; Melo Neto et al., 2008; Uno, 1998), the ultimate shrinkage strain on the mortar gradually diminished as the $\mathrm{W} / \mathrm{C}$ decreased since the mortar specimens with a lower $\mathrm{W} / \mathrm{C}$ had less free water to evaporate during the drying period and thus showed lower shrinkage strain. More importantly, the USS on the mortar significantly declined as the volume of the FNS increased. For example, at a W/C of 0.40 , the ultimate shrinkage strain on the mortar decreased from 1284 to $489 \mu \varepsilon$ when the volume of the FNS increased up to $20 \%$.

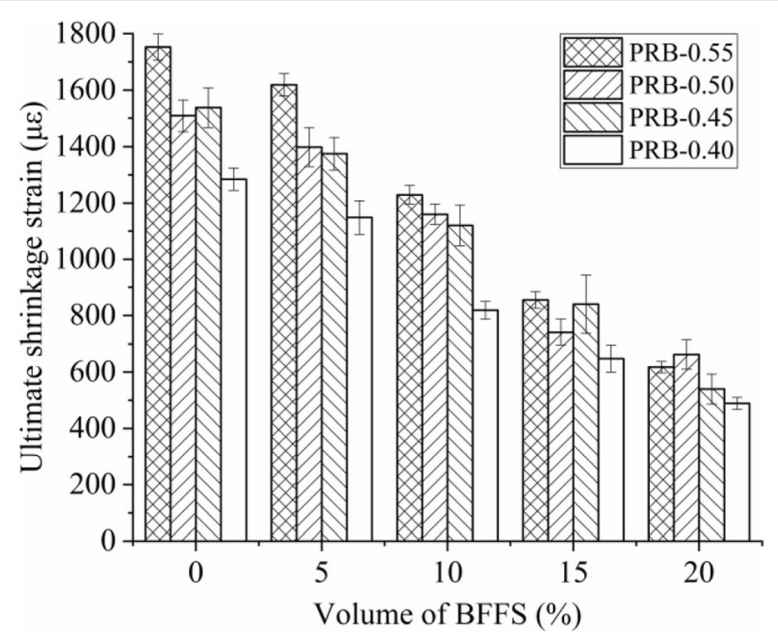

Fig. 8 The ultimate shrinkage strain on the mortar samples versus the volume of the FNS at various water-to-cement ratios 
To further analyze the effect of incorporating the FNS as a substitute for the paste on limiting the drying shrinkage strain on the mortar, the rate of decrease in the USS against the volume of the FNS is illustrated in Fig. 9. The rate of decrease in the ultimate shrinkage strain on the mortar generally increased as the volume of the FNS rose at a W/C in the range of 0.40 to 0.55 .

As presented in Table 2, the addition of the FNS could significantly reduce the volume of the WPC the clinker of which was linked to shrinkage. Therefore, the shrinkage strain on the mortar mix was reduced to some extent during the drying period (Kwan et al., 2013). Furthermore, the tiny particles of the FNS could act as a micro-skeleton when filling the voids of the fine aggregate and thus could produce an additional effect to further restrict the shrinkage strain on the cement paste. As a result, the ultimate shrinkage strain on the mortar decreased, indicating that the microstructure of the mortar had fewer microdefects and exhibited stronger mechanical properties (Ling and Kwan, 2016).

Whether ferronickel slag was recycled as a replacement for cement (You et al., 2019) or a substitute for aggregate (Saha et al., 2018), it enhanced the resistance of the mortar or concrete to shrinkage in the existing researches. Moderate development of shrinkage in the mortar versus time is comparatively conducive to relieving the tensile stress caused by the deformation due to the shrinkage, so a larger number of shrinkage cracks in the mortar or concrete can be avoided (Gonzalez-Corominas and Etxeberria, 2016; Samouh et al., 2019, 2017).

\subsection{Pore structure of mortar}

The testing results of mercury intrusion porosimetry such as pore size distribution and porosity are illustrated in Fig. 10. Wu et al. (1999) classified the pore size of cement paste under four ranges, including $d<20 \mathrm{~nm}$ (harmless pores), $20 \mathrm{~nm}<d<$ $50 \mathrm{~nm}$ (little harmful pores), $50 \mathrm{~nm}<d<200 \mathrm{~nm}$ (harmful pores), and $d>200 \mathrm{~nm}$ (very harmful pores).

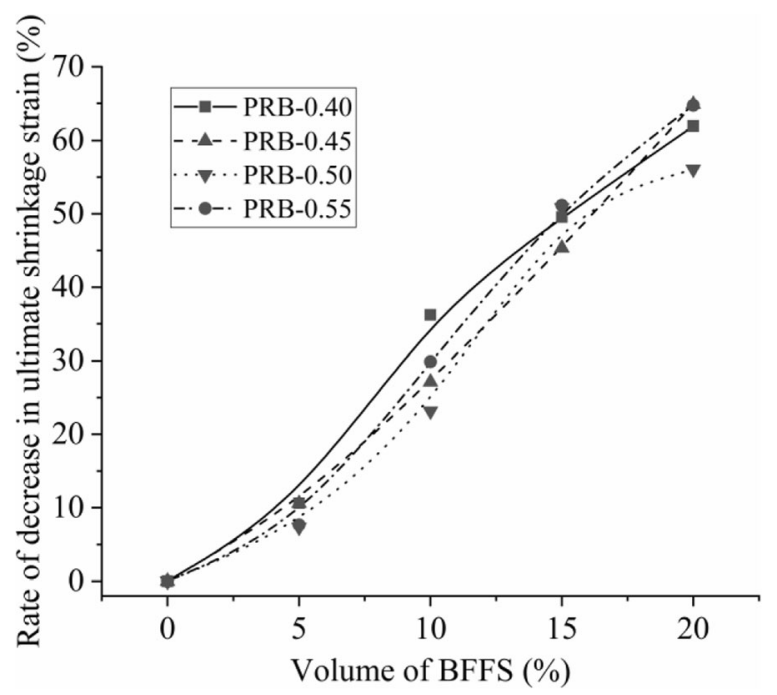

Fig. 9 The rate of decrease in ultimate shrinkage strain on the mortar versus the volume of the FNS at various water-to-cement ratios 


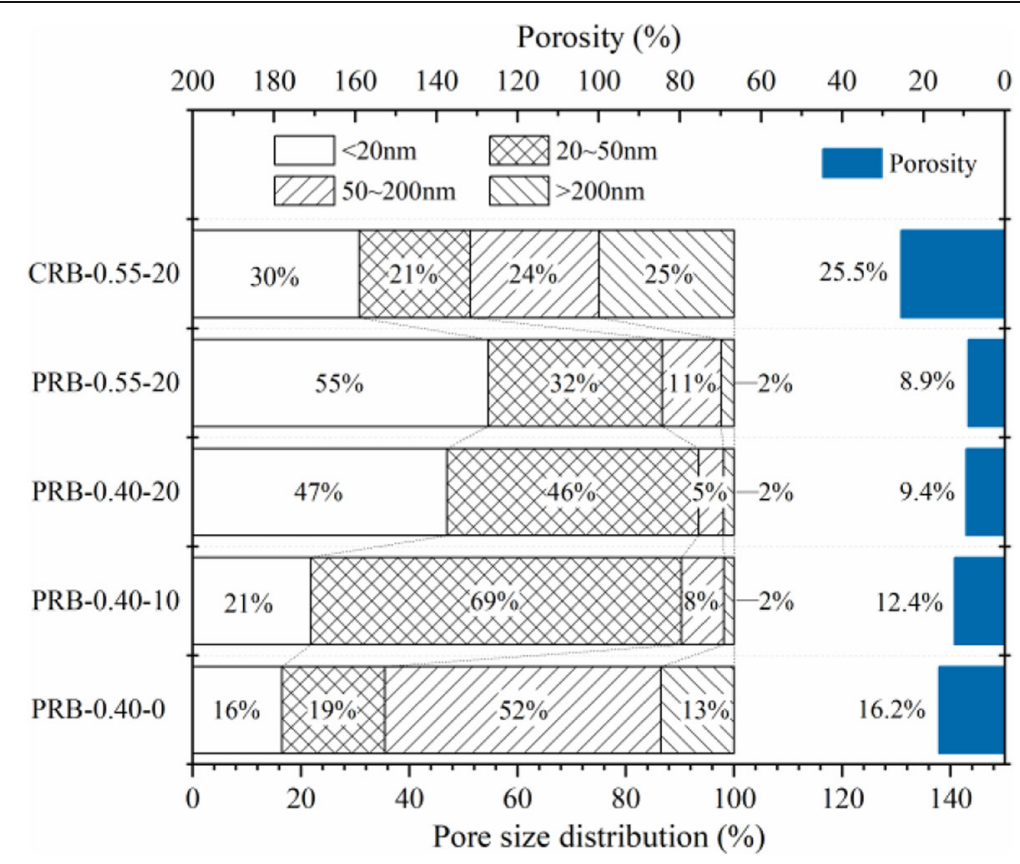

Fig. 10 The porosity and pore size distribution of the cement paste cured for 28 days

First, the porosity of sample PRB- 0.40 decreased prominently from $16.2 \%$ to $9.4 \%$ as the volume of the FNS increased. The dominating pores of sample PRB-0.40-0 had a diameter of larger than $200 \mathrm{~nm}$, that is, they were mainly the very harmful pores, and the total percentage of the pores with a diameter of smaller than $20 \mathrm{~nm}$ and a diameter in the range of $20-50 \mathrm{~nm}$ was only approximately $35 \%$. When the volume of the FNS increased from $0 \%$ to $10 \%$, the proportion of the very harmful pores showed a sharp decline and plummeted to $2 \%$. Correspondingly, the volume fraction of the little harmful pores and the harmless pores soared from $19 \%$ to $69 \%$ and from $16 \%$ to $21 \%$ respectively. When the volume of the FNS increased to $20 \%$, the volume ratios of the harmful pores and the little harmful pores diminished, but the proportion of the harmless pores increased from $21 \%$ to $47 \%$, indicating that adding the FNS as a substitute for the paste could effectively refine the pore structure of the cement paste.

Comparing the results of sample PRB-0.40-20 with those of sample PRB-0.55-20 revealed that adding the FNS to the mortar produced at a higher W/C resulted in a more significant improvement in porosity refinement. For example, the porosity of samples PRB-0.40-20 and PRB-0.55-20 was 9.4\% and 8.9\% respectively.

Nonetheless, when the FNS was utilized by the cement replacement strategy, the samples did not show such a remarked improvement on the refinement of the pore structure of the mortar. The volume fraction of the four types of the pores of CRB0.55-20 was close to each other, and the volume fraction of the pores with a diameter of larger than $200 \mathrm{~nm}$ and those with a diameter in the range of $50-200 \mathrm{~nm}$ was $25 \%$ and $24 \%$ respectively, while the porosity of the sample was still $25.5 \%$. Hence, the pore structure of the mortar produced by the paste replacement method was much denser than that of the mortar produced by the cement replacement method. As a macroscopic reflection of the microstructure refinement, the strength of the mortar improved, and both the fluid (water and carbon dioxide) permeability of the mortar and 
its shrinkage deformation decreased. As discussed above, the drying shrinkage of mortar sample is primarily affected by the phase formation and porosity as well as pore size distribution of the mixture. Larger capillary stress would be caused in smaller pores as the water evaporated, which may generate larger shrinkage strain. But as the porosity decreased and the pore size distribution refined, it is more difficult for the free water inside the mixture to escape to the external environment. Under the combined action of these factors, the drying shrinkage strain of sample finally exhibited a downward trend.

\section{Cement consumption and performance improvement}

To analyze the difference between the paste replacement method and the cement replacement method in terms of saving cement consumption, the data given in the last column of Table 2 present the rate of decrease in the white cement in each mortar mix. It demonstrates that the paste replacement method is more effective in reducing the consumption of white cement and in recycling the FNS than the cement replacement method. For example, the paste replacement method could save 33 vol\% of the white cement by incorporating $20 \mathrm{vol} \%$ of the FNS, while the cement replacement method could only save 20 vol\% of the white cement by incorporating $20 \mathrm{vol} \%$ of the FNS. Based on the third column of Table 2, the cement content of each mix proportion is presented in Fig. 11. It clearly shows that the WPC content of the mortar was higher at a lower $\mathrm{W} / \mathrm{C}$ and decreased as the volume of the FNS increased at a constant $\mathrm{W} / \mathrm{C}$, whether the mortar specimens were produced by the paste replacement method or by the cement replacement method. More importantly, we can deduce from the cross point in Fig. 11 that at an FNS volume fraction of 20\%, the WPC content of PRB- 0.40 decreased to the equal WPC content of CRB-0.55. In other words, the paste replacement method is more effective in reducing the cement content and construction cost than the cement replacement method.

In addition to the data on the reduction of the cement content, the testing results of the durability of the mortars also demonstrate that the paste replacement method is a

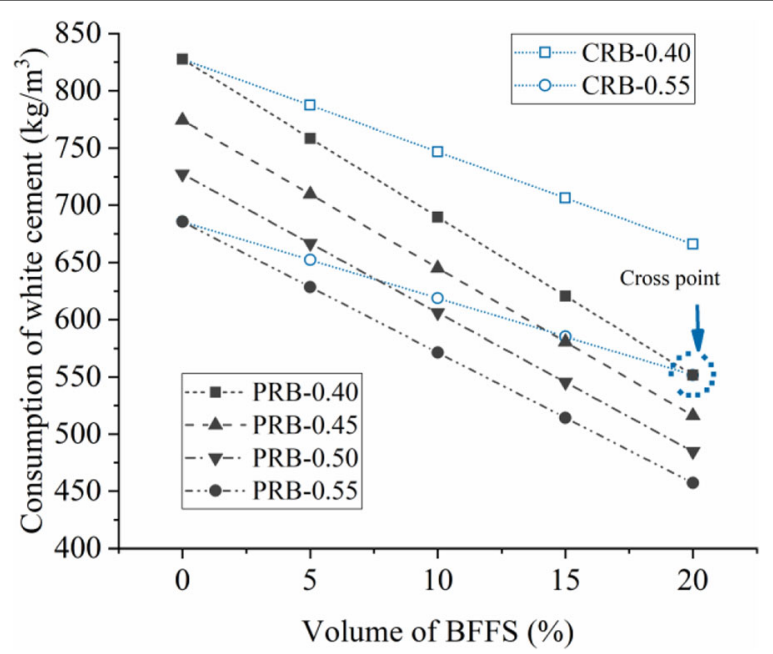

Fig. 11 The consumption of white Portland cement versus the volume of the FNS at various water-to-cement ratios 
better strategy for utilizing the recycled FNS than the cement replacement method. Figures $12,13,14,15$ respectively elucidate the relationship between the carbonation depth, IWAR, SWAR, and USS of the mortar and the WPC content of the mortar at various volumes of the FNS and different water-to-cement ratios. It is visually obvious that increasing the volume of the FNS from $0 \%$ to $20 \%$ not only reduced the WPC content of the mortar and carbon dioxide emissions but also could decrease the carbonation depth, IWAR, SWAR, and USS of the mortar. Enhanced durability means a longer service life for concrete and a smaller amount of construction waste generated from the demolition of abandoned buildings. Although decreasing the W/C could improve the durability of the mortar, it increased the cement consumption.

In addition, the relationship between the cement content and the strength of the mortar should be discussed. To compare the paste replacement method with the cement replacement method, Fig. 16 depicts the 28-day compressive strength of the PRB and CRB mortar samples. It is obvious that adding the FNS as a replacement for the paste could increase the compressive strength of the mortar while reducing the cement content; however, using the FNS as a substitute for the cement could only maintain the compressive strength of the mortar basically unchanged and could reduce a limited amount of the cement. In other words, the ratio of the cement content to the compressive strength of the PRB samples was higher than that of the CRB samples, which implies that, to satisfy the same design strength, the paste replacement method requires a smaller amount of cement in the unit volume of concrete and thus reduces the amount of concrete in structures.

\section{Discussion}

In this work, blast furnace ferronickel slag was utilized for replacing the total volume of the white Portland cement and water to reduce cement consumption. Compared to the

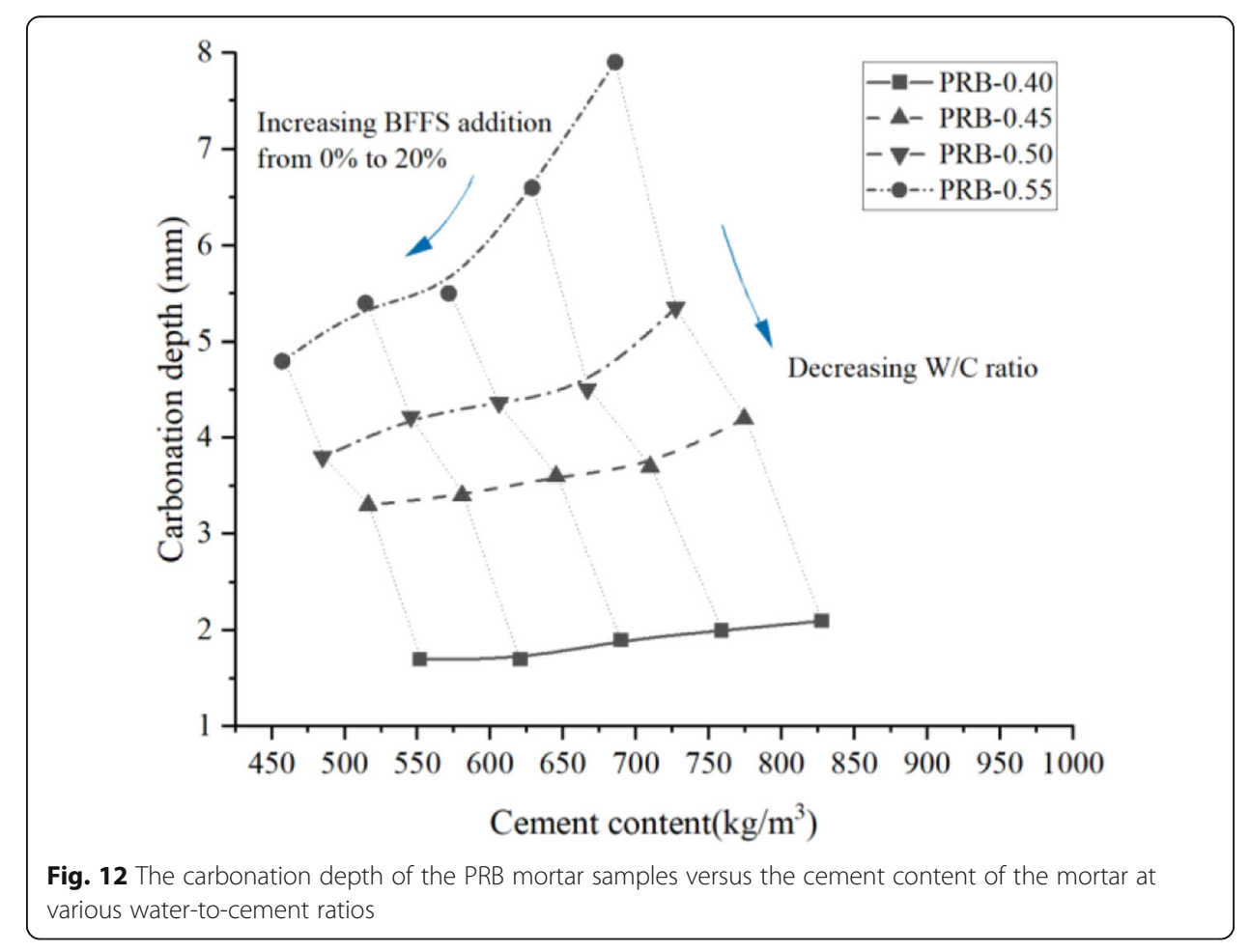




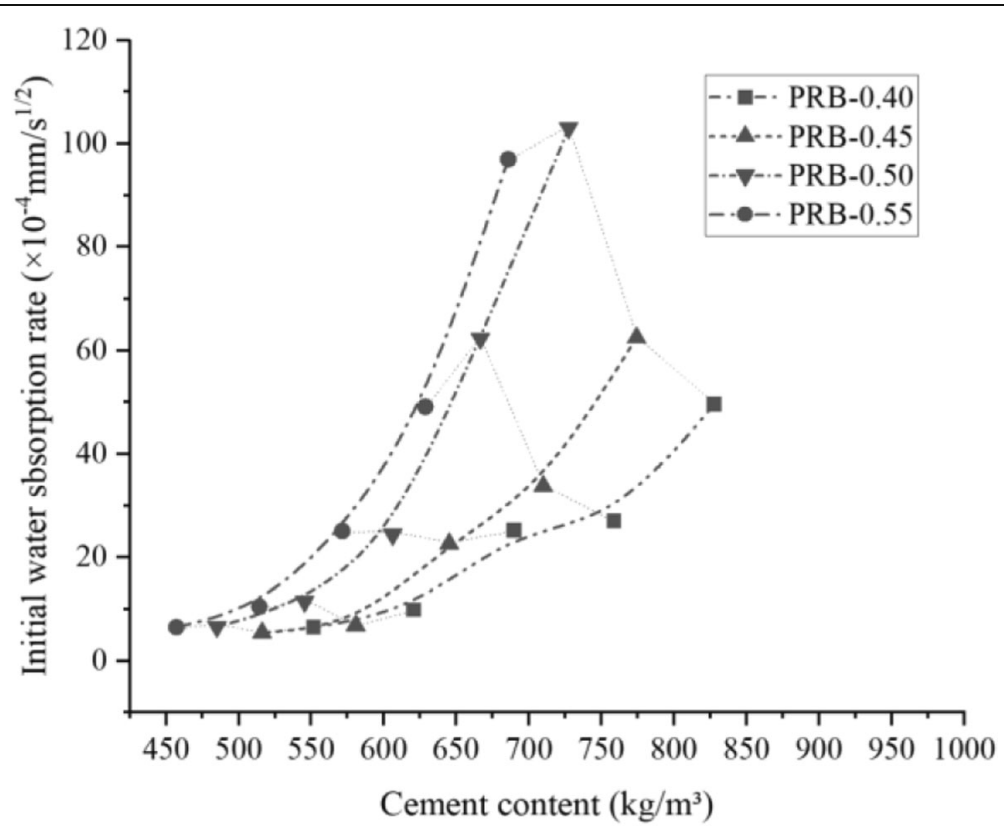

Fig. 13 The initial water absorption of the PRB mortar samples versus the cement content of the mortar at various water-to-cement ratios

cement replacement method, the paste replacement method researched in this study could effectively improve the strength of the mortar and could reduce the drying shrinkage strain on the mortar and its carbon dioxide and water permeability while decreasing the cement content of the mortar by as high as 33 vol\%. Therefore, we could conclude that recycling FNS to replace cement in mortar is an environmentally friendly and economical method. In fact, the mechanism by which this method can provide such benefits can be summarized as two points: the pozzolanic activity of FNS and the reduction of water consumption.

\subsection{Pozzolanic activity of FNS}

According to the works of Wang et al. (Huang et al., 2017; Rahman et al., 2017; Wang et al., 2018a, b; Yang et al., 2014), FNS can be recycled as a supplementary cementing material $(\mathrm{SCM})$ because this waste residue generally contains a large percentage of amorphous phases such as $\mathrm{CaO}$ and $\mathrm{Al}_{2} \mathrm{O}_{3}$ and thus has significant pozzolanic activity. When it is added to the hydration environment of Portland cement, it can react with $\mathrm{Ca}(\mathrm{OH})_{2}$ produced from the hydration of Portland cement and can produce calcium-silicate-hydrate (C-S-H) gel with a lower calciumto-silicon ratio $(\mathrm{Ca} / \mathrm{Si})$ and silicate chains having a higher degree of polymerization.

Figure 2 illustrates that the particles of the FNS with a Blaine fineness value of $384 \mathrm{~cm}^{2} / \mathrm{g}$ are finer than those of the WPC; hence, the voids of the WPC can be filled by the FNS particles, so the bulk density of the mortar improves. Simultaneously, some particles of the FNS are so small that part of the FNS can enhance the hydration degree of the WPC by acting as nuclei to help portlandite and C-S$\mathrm{H}$ gel precipitate (Chen et al., 2019). 


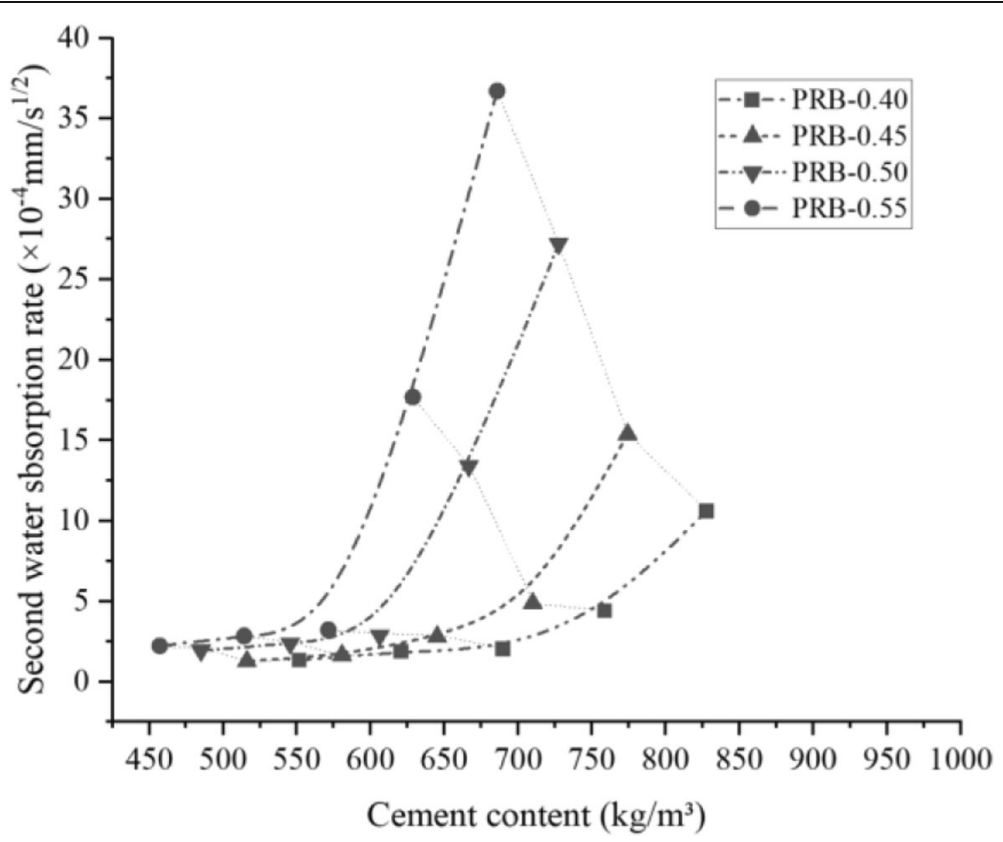

Fig. 14 The second water absorption of the PRB mortar samples versus the cement content of the mortar at various water-to-cement ratios

More importantly, the WPC contains $8.8 \%$ of calcite and $3.74 \%$ of $\mathrm{SO}_{3}$, but the FNS is composed of $\mathrm{SO}_{3}(4.14 \%)$ and $\mathrm{Al}_{2} \mathrm{O}_{3}$ (20.92\%), indicating that it mainly consists of amorphous alumina except for a small amount of spinel. In the hydration process, these components react with portlandite and free water to form an extra ettringite and carboaluminate phase (Machner et al., 2017; Palou et al., 2018). The XRD patterns reported in some previous researches (Kim et al., 2019; B. Li et al., 2019a, b, c, d, e, f)

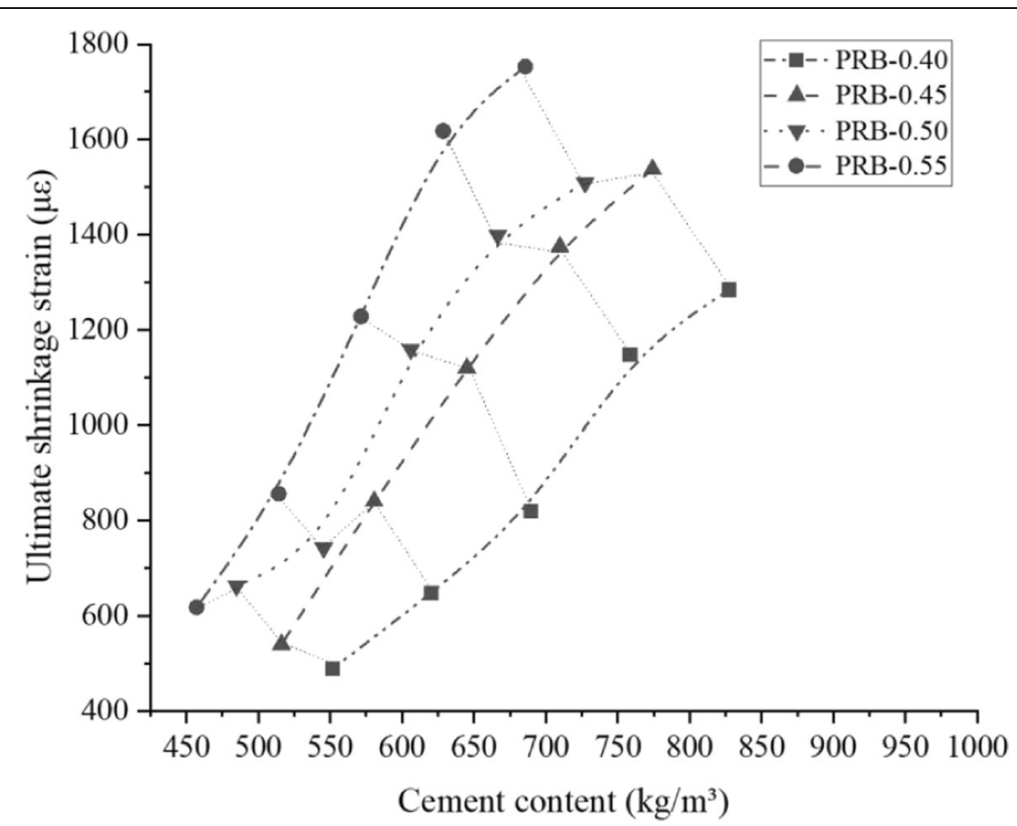

Fig. 15 The ultimate shrinkage strain on the PRB mortar samples versus the cement content of the mortar at various water-to-cement ratios 


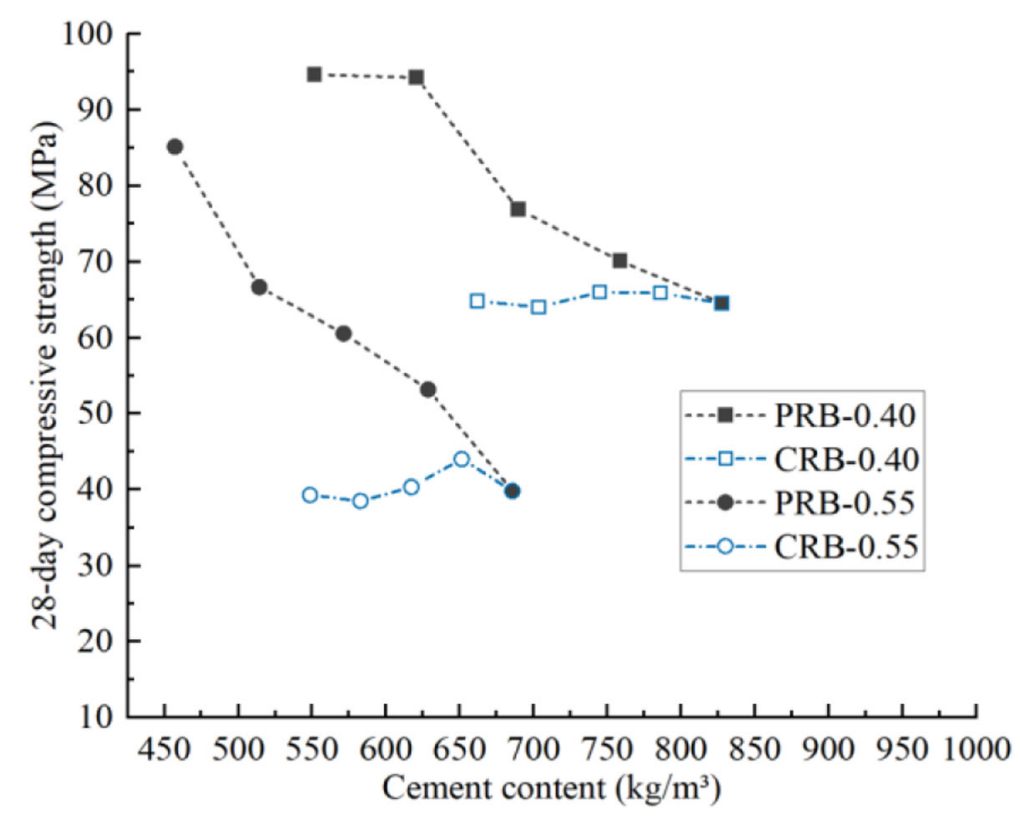

Fig. 16 The 28-day compressive strength of the PRB and CRB mortar samples versus the cement content of the mortar at W/C of 0.40 and 0.55

confirmed the obvious diffraction peak of carboaluminate in a $2 \theta$ angle range of $10.5^{\circ}$ to $11.5^{\circ}$ and clearly showed the ettringite stabilization (Krishnan and Bishnoi, 2018). These intricate additional reactions consume the free water and generate a higher amount of hydration products to fill the space that was originally occupied by the free water, which leads to two physical effects (Mehta and Monteiro, 1993): porosity refinement and particle size refinement. In general, such a refinement of porosity and particle size can strengthen the interfacial transition zone (ITZ) and can reduce the number of microcracks, so the strength and permeability of mortar or concrete can be enhanced. Moreover, the generation of a higher amount of ettringite can offset part of the drying shrinkage strain (Qian et al., 2017), and more consumption of the free water can reduce the evaporable water in capillary porosity. Hence, the sample with a higher amount of the blast furnace ferronickel slag has lower ultimate shrinkage strain.

\subsection{Water consumption}

When the FNS was added to replace an equal volume of the paste, the water-tocement ratio did not change since the volume of the water and white cement was substituted correspondingly. However, the consumption of water decreased, but the powder volume (the total volume of the WPC and the FNS) increased; thus, the waterto-powder ratio by weight declined. A lower water-to-powder ratio could produce a higher amount of hydration products and could form a denser microstructure, resulting in an improvement in the compressive strength of the samples. Figure 17 correlates the water demand with the mechanical properties, where the 28-day compressive strength of the mortar improves as the water demand decreases. Meanwhile, a lower water-topowder ratio could reduce the bleeding risk and could enhance the volume stability and durability of the mortar mix. 


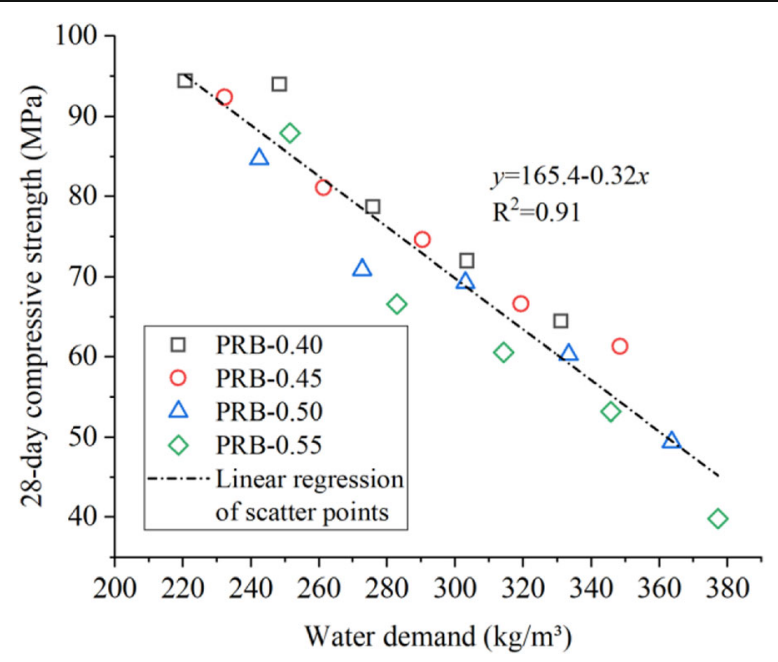

Fig. 17 The linear regression between the water demand and the 28-day compressive strength of the mortar

On the other hand, we can realize that the workability of the mortar produced by the paste replacement method was conspicuously reduced, especially at a high volume of the FNS. As tabulated in Table 3, an increasing dosage of the superplasticizer was used to achieve the required slump flow as the volume of the FNS increased. To overcome this disadvantage, some research on the paste replacement method have suggested adding powder (inert) materials with fine and spherical particles to the paste to improve its workability.

\section{Implications}

Overall, it is a more effective and promising strategy to produce a more environmentally friendly and economical mortar by recycling and using the FNS or any other available by-products as a replacement for the paste in the mortar so as to reduce the consumption of white Portland cement. In recent years, some major bridges such as landmark cable-stayed bridges and suspension bridges are expected to have white and clean bridge towers constructed mainly by white cementitious concrete, but the high cost of the production is the first obstacle. The research achievements in this study can provide useful information on how to tackle the cost challenge without significant damage to the aesthetic appearance of constructions and can be conducive to the utilization of by-products and the reduction of carbon footprint.

\section{Conclusions}

In the current work, 25 mortar mixes were prepared to systematically explore the effects of the addition of FNS on the strength and durability of mortar. From the findings obtained, the following conclusions are drawn:

(1) A higher incorporation of the FNS as a substitute for the paste increased the required dosage of the superplasticizer. 
(2) The reduction of the W/C could significantly improve the carbon dioxide and water permeability of the mortar and could reduce its drying shrinkage strain; however, it resulted in consuming more white Portland cement correspondingly.

(3) The incorporation of the FNS substantially increased the compressive strength of the mortar, which was beneficial to decreasing its carbonation depth, water absorption, and drying shrinkage strain. Conversely, incorporating the FNS into the mortar by the cement replacement method to replace the white cement could only maintain the compressive strength of the mortar unchanged.

(4) Increasing the volume of the FNS as a substitute for the paste could refine the porosity and could increase the number of harmless pores and little harmful pores; also, the effect of porosity refinement was more significant in the samples with a higher water-to-cement ratio.

(5) In addition to the above improvement in the strength and durability of the mortar, the consumption of the white Portland cement was reduced by as high as 33 vol\%.

\footnotetext{
Abbreviations

$C_{2}$ S: Dicalcium Silicate; $C_{3} A$ : Tricalcium Aluminate; $C_{3}$ S: Tricalcium Silicate; $C_{4} A F$ : Tetra-Calcium Aluminoferrite; $C a /$ Si: Calcium-to-Silicon Ratio; C-S-H: Calcium-Silicate-Hydrate; FNS: Blast Furnace Ferronickel Slag; ITZ: Interfacial Transition Zone; IWAR: Initial Water Absorption Rate; MIP: Mercury Intrusion Porosimetry; PSD: Particle Size Distribution; SEM: Scanning Electron Microscopy; SP: Superplasticizer; SWAR: Second Water Absorption Rate; USS: Ultimate Shrinkage Strain; W/C: Water-to-Cement Ratio; WPC: White Portland Cement; XRF: X-ray Fluorescence Spectrometer
}

Acknowledgements

Not applicable.

\title{
Authors' contributions
}

QingFeng Guan: Investigation, Data Curation, Formal analysis, Writing - Original Draft and Visualization. JingLiang Xia: Term, Resources, Funding acquisition and Supervision. Faguang Leng: Resources, Funding acquisition and Supervision. YongXiang Zhou: Conceptualization, Methodology, Funding acquisition, Writing - Review \& Editing and Supervision. The authors read and approved the final manuscript.

Funding

This research was supported by the National Natural Science Foundation of China (51978408) and National Key R\&D Program of China 2016YFC0701000

Availability of data and materials

Not applicable.

Competing interests

The author declare that they have no competing interests.

\author{
Author details \\ ${ }^{1}$ Institute of Building Materials, China Academy of Building Research, Beijing, China. ${ }^{2}$ National Engineering Research \\ Center of Building Technology, Beijing, China. ${ }^{3}$ State Key Laboratory of Building Safety and Built Environment, Beijing, \\ China.
}

Received: 27 February 2021 Accepted: 21 March 2021

Published online: 06 May 2021

\section{References}

ASTM C1585-13 (2013) Standard test method for measurement of rate of absorption of water by hydraulic cement concretes. ASTM Int. https://doi.org/10.1520/C1585-13.2

Balonis M (2019) Thermodynamic modelling of temperature effects on the mineralogy of Portland cement systems containing chloride. Cem Concr Res 120:66-76. https://doi.org/10.1016/j.cemconres.2019.03.011

Chen JJ, Kwan AKH, Jiang Y (2014) Adding limestone fines as cement paste replacement to reduce water permeability and sorptivity of concrete. Constr Build Mater 56:87-93. https://doi.org/10.1016/j.conbuildmat.2014.01.066

Chen JJ, Ng PL, Kwan AKH, Li LG (2019) Lowering cement content in mortar by adding superfine zeolite as cement replacement and optimizing mixture proportions. J Clean Prod 210:66-76. https://doi.org/10.1016/j.jclepro.2018.11.007

Choi YC, Choi S (2015) Alkali-silica reactivity of cementitious materials using ferro-nickel slag fine aggregates produced in different cooling conditions. Constr Build Mater 99:279-287. https://doi.org/10.1016/j.conbuildmat.2015.09.039

Cohen MD, Kargacin B, Klein CB, Costa M (1993) Mechanisms of chromium carcinogenicity and toxicity. Crit Rev Toxicol 23(3): 255-281. https://doi.org/10.3109/10408449309105012 
Dhal B, Thatoi HN, Das NN, Pandey BD (2013) Chemical and microbial remediation of hexavalent chromium from contaminated soil and mining/metallurgical solid waste: a review. J Hazard Mater 250-251:272-291. https://doi.org/10.1 016/j.jhazmat.2013.01.048

GB/T 50082-2009 (2009) Standard for test methods of long-term performance and durability of ordinary concrete. Minist. Hous. Urban-Rural Dev, Peoples Repub. China

Gonzalez-Corominas A, Etxeberria M (2016) Effects of using recycled concrete aggregates on the shrinkage of high performance concrete. Constr Build Mater 115:32-41. https://doi.org/10.1016/j.conbuildmat.2016.04.031

Hamad BS (1995) Investigations of chemical and physical properties of white cement concrete. Adv Cem Based Mater 2(4): 161-167. https://doi.org/10.1016/1065-7355(95)90017-9

Honglei C, Zuquan J, Tiejun Z, Benzhen W, Zhe L, Jian L (2020) Capillary suction induced water absorption and chloride transport in non-saturated concrete: the influence of humidity, mineral admixtures and sulfate ions. Constr Build Mater 236:117581. https://doi.org/10.1016/j.conbuildmat.2019.117581

Huang Y, Wang Q, Shi M (2017) Characteristics and reactivity of ferronickel slag powder. Constr Build Mater 156:773-789. https://doi.org/10.1016/j.conbuildmat.2017.09.038

Jaafri R, Aboulayt A, Alam SY, Roziere E, Loukili A (2019) Natural hydraulic lime for blended cement mortars: behavior from fresh to hardened states. Cem Concr Res 120:52-65. https://doi.org/10.1016/j.cemconres.2019.03.003

$J G J / T$ 70-2009, Standard for test method of performance on building mortar, 2009

Jie WZ, Wen N, Yan J, Ping ZL, Yan HX (2010) Crystallization behavior of glass ceramics prepared from the mixture of nickel slag, blast furnace slag and quartz sand. J Non-Cryst Solids 356(31-32):1554-1558. https://doi.org/10.1016/j.jnoncrysol.201 0.05 .063

Jiménez-Quero VG, León-Martínez FM, Montes-García P, Gaona-Tiburcio C, Chacón-Nava JG (2013) Influence of sugar-cane bagasse ash and fly ash on the rheological behavior of cement pastes and mortars. Constr Build Mater 40:691-701. https://doi.org/10.1016/j.conbuildmat.2012.11.023

Júlio E, Dias N, Lourenço J, Silva J (2006) Feret coefficients for white self-compacting concrete. Mater Struct Constr 39:585591. https://doi.org/10.1617/s11527-005-9048-x

Katsiotis NS, Tsakiridis PE, Velissariou D, Katsiotis MS, Alhassan SM, Beazi M (2015) Utilization of ferronickel slag as additive in Portland cement: a hydration leaching study. Waste Biomass Valorization 6(2):177-189. https://doi.org/10.1007/s12649-01 5-9346-7

Kim H, Lee CH, Ann KY (2019) Feasibility of ferronickel slag powder for cementitious binder in concrete mix. Constr Build Mater 207:693-705. https://doi.org/10.1016/j.conbuildmat.2019.02.166

Krishnan S, Bishnoi S (2018) Understanding the hydration of dolomite in cementitious systems with reactive aluminosilicates such as calcined clay. Cem Concr Res 108:116-128. https://doi.org/10.1016/j.cemconres.2018.03.010

Kwan AKH, Mckinley M, Chen JJ (2013) Adding limestone fines as cement paste replacement to reduce shrinkage of concrete. Mag Concr Res 65(15):942-950. https://doi.org/10.1680/macr.13.00028

Lavado J, Bogas J, de Brito J, Hawreen A (2020) Fresh properties of recycled aggregate concrete. Constr Build Mater 233: 117322. https://doi.org/10.1016/j.conbuildmat.2019.117322

Lemonis N, Tsakiridis PE, Katsiotis NS, Antiohos S, Papageorgiou D, Katsiotis MS, Beazi-Katsioti M (2015) Hydration study of ternary blended cements containing ferronickel slag and natural pozzolan. Constr Build Mater 81:130-139. https://doi. org/10.1016/j.conbuildmat.2015.02.046

Li B, Huo B, Cao R, Wang S, Zhang Y (2019a) Sulfate resistance of steam cured ferronickel slag blended cement mortar. Cem Concr Compos 96:204-211. https://doi.org/10.1016/j.cemconcomp.2018.12.001

Li LG, Feng J-J, Zhu J, Chu S-H, Kwan AK (2019b) Pervious concrete: effects of porosity on permeability and strength. Mag Concr Res 73(2):69-79. https://doi.org/10.1680/jmacr.19.00194

Li LG, Huang ZH, Tan YP, Kwan AK, Liu F (2018a) Use of marble dust as paste replacement for recycling waste and improving durability and dimensional stability of mortar. Constr Build Mater 166:423-432. https://doi.org/10.1016/j.conbuildmat.2018.01.154

Li LG, Huang ZH, Tan YP, Kwan AKH, Chen HY (2019c) Recycling of marble dust as paste replacement for improving strength, microstructure and eco-friendliness of mortar. J Clean Prod 210:55-65. https://doi.org/10.1016/j.jclepro.2018.10.332

Li LG, Kwan AKH (2011) Mortar design based on water film thickness. Constr Build Mater 25(5):2381-2390. https://doi.org/10.1 016/j.conbuildmat.2010.11.038

Li LG, Ouyang Y, Zhuo Z-Y, Kwan AK (2021a) Adding ceramic polishing waste as filler to reduce paste volume and improve carbonation and water resistances of mortar. Adv Bridge Eng 2(1):3. https://doi.org/10.1186/s43251-020-00019-2

Li LG, Wang YM, Tan YP, Kwan AK, Li LJ (2018b) Adding granite dust as paste replacement to improve durability and dimensional stability of mortar. Powder Technol 333:269-276. https://doi.org/10.1016/j.powtec.2018.04.055

Li LG, Wang YM, Tan YP, Kwan AKH (2019d) Filler technology of adding granite dust to reduce cement content and increase strength of mortar. Powder Technol 342:388-396. https://doi.org/10.1016/j.powtec.2018.09.084

Li LG, Xiao BF, Fang ZQ, Xiong Z, Chu SH, Kwan AK (2021b) Feasibility of glass/basalt fiber reinforced seawater coral sand mortar for 3D printing. Add Manufact 37:101684. https://doi.org/10.1016/j.addma.2020.101684

Li LG, Zheng JY, Ng P-L, Kwan AK (2021c) Synergistic cementing efficiencies of nano-silica and micro-silica in carbonation resistance and sorptivity of concrete. J Build Eng 33:101862. https://doi.org/10.1016/j.jobe.2020.101862

Li LG, Zheng JY, Ng PL, Zhu J, Kwan AKH (2019e) Cementing efficiencies and synergistic roles of silica fume and nano-silica in sulphate and chloride resistance of concrete. Constr Build Mater 223:965-975. https://doi.org/10.1016/j.conbuildmat.2 019.07.241

Li LG, Zheng JY, Zhu J, Kwan AKH (2018) Combined usage of micro-silica and nano-silica in concrete: SP demand, cementing efficiencies and synergistic effect. Constr Build Mater 168:622-632. https://doi.org/10.1016/j.conbuildmat.2018.02.181

Li LG, Zhuo ZY, Zhu J, Chen JJ, Kwan AKH (2019f) Reutilizing ceramic polishing waste as powder filler in mortar to reduce cement content by 33\% and increase strength by 85\%. Powder Technol 355:119-126. https://doi.org/10.1016/j.powtec.2 019.07 .043

Li LG, Zhuo ZY, Zhu J, Kwan AKH (2020) Adding ceramic polishing waste as paste substitute to improve sulphate and shrinkage resistances of mortar. Powder Technol 362:149-156. https://doi.org/10.1016/j.powtec.2019.11.117

Ling SK, Kwan AKH (2016) Adding limestone fines as cementitious paste replacement to lower carbon footprint of SCC. Constr Build Mater 111:326-336. https://doi.org/10.1016/j.conbuildmat.2016.02.072 
Machner A, Zajac M, Ben Haha M, Kjellsen KO, Geiker MR, De Weerdt K (2017) Portland metakaolin cement containing dolomite or limestone - similarities and differences in phase assemblage and compressive strength. Constr Build Mater 157:214-225. https://doi.org/10.1016/j.conbuildmat.2017.09.056

Maltese C, Pistolesi C, Lolli A, Bravo A, Cerulli T, Salvioni D (2005) Combined effect of expansive and shrinkage reducing admixtures to obtain stable and durable mortars. Cem Concr Res 35(12):2244-2251. https://doi.org/10.1016/j.cemconres.2 004.11 .021

Mehta P, Monteiro P (1993) Concrete structure, properties and materials. Prentice Halllnc, London

Melo Neto AA, Cincotto MA, Repette W (2008) Drying and autogenous shrinkage of pastes and mortars with activated slag cement. Cem Concr Res 38(4):565-574. https://doi.org/10.1016/j.cemconres.2007.11.002

Nežerka V, Bilý P, Hrbek V, Fládr J (2019) Impact of silica fume, fly ash, and metakaolin on the thickness and strength of the ITZ in concrete. Cem Concr Compos 103:252-262. https://doi.org/10.1016/j.cemconcomp.2019.05.012

Nguyen QD, Khan MSH, Castel A, Kim T (2019) Durability and microstructure properties of low-carbon concrete incorporating ferronickel slag sand and Fly ash. J Mater Civ Eng 31(8):1-13. https://doi.org/10.1061/(ASCE)MT.1943-5533.0002797

Palou M, Kuzielová E, Žemlička M, Novotný R, Másilko J (2018) The effect of metakaolin upon the formation of ettringite in metakaolin-lime-gypsum ternary systems. J Therm Anal Calorim 133(1):77-86. https://doi.org/10.1007/s10973-017-6885-0

Park RM (2013) Neurobehavioral deficits and parkinsonism in occupations with manganese exposure: a review of methodological issues in the epidemiological literature. Safety Health Work 4(3):123-135. https://doi.org/10.1016/j.shaw.2 013.07.003

Peng L, Ma Z, Xie Y (2015) Preliminary study on the preparation of self-compacting concrete used by ferronickel slag micro powder. In: 1st Conference on Solid Waste Utilization and Eco-materials. Chinese Ceramic Society, Beijing

Qian J, Yu J, Sun H, Ma Y (2017) Formation and function of Ettringite in cement hydrates. J Chin Ceram Soc 45:1569-1581. https://doi.org/10.14062/j.issn.0454-5648.2017.11.04

Rahman MA, Sarker PK, Shaikh FUA, Saha AK (2017) Soundness and compressive strength of Portland cement blended with ground granulated ferronickel slag. Constr Build Mater 140:194-202. https://doi.org/10.1016/j.conbuildmat.2017.02.023

Saha AK, Khan MNN, Sarker PK (2018) Value added utilization of by-product electric furnace ferronickel slag as construction materials: a review. Resour Conserv Recycl 134:10-24. https://doi.org/10.1016/j.resconrec.2018.02.034

Saha AK, Sarker PK (2016) Expansion due to alkali-silica reaction of ferronickel slag fine aggregate in OPC and blended cement mortars. Constr Build Mater 123:135-142. https://doi.org/10.1016/..conbuildmat.2016.06.144

Saha AK, Sarker PK (2017) Sustainable use of ferronickel slag fine aggregate and fly ash in structural concrete: mechanical properties and leaching study. J Clean Prod 162:438-448. https://doi.org/10.1016/j.jclepro.2017.06.035

Saha AK, Sarker PK, Majhi S (2019) Effect of elevated temperatures on concrete incorporating ferronickel slag as fine aggregate. Fire Mat 43(1):8-21. https://doi.org/10.1002/fam.2664

Samouh H, Rozière E, Loukili A (2019) Experimental and numerical study of the relative humidity effect on drying shrinkage and cracking of self-consolidating concrete. Cem Concr Res 115:519-529. https://doi.org/10.1016/j.cemconres.2018.08.008

Samouh H, Rozière E, Wisniewski V, Loukili A (2017) Consequences of longer sealed curing on drying shrinkage, cracking and carbonation of concrete. Cem Concr Res 95:117-131. https://doi.org/10.1016/j.cemconres.2017.02.019

Shen D, Jiao Y, Kang J, Feng Z, Shen Y (2020a) Influence of ground granulated blast furnace slag on early-age cracking potential of internally cured high performance concrete. Constr Build Mater 233:117083. https://doi.org/10.1016/j. conbuildmat.2019.117083

Shen L, Li Q, Ge W, Xu S (2020b) The mechanical property and frost resistance of roller compacted concrete by mixing silica fume and limestone powder: experimental study. Constr Build Mater 239:117882. https://doi.org/10.1016/j.conbuildmat.2 019.117882

Zhuang S, Wang Q (2021) Inhibition mechanisms of steel slag on the early-age hydration of cement. Cem Concr Res 140: 106283. https://doi.org/10.1016/j.cemconres.2020.106283

Suleiman AR, Nelson AJ, Nehdi ML (2019) Visualization and quantification of crack self-healing in cement-based materials incorporating different minerals. Cem Concr Compos 103:49-58. https://doi.org/10.1016/j.cemconcomp.2019.04.026

Sun J, Feng J, Chen Z (2019) Effect of ferronickel slag as fine aggregate on properties of concrete. Constr Build Mater 206: 201-209. https://doi.org/10.1016/j.conbuildmat.2019.01.187

Tziotziou M, Karakosta E, Karatasios I, Diamantopoulos G, Sapalidis A, Fardis M, Maravelaki-Kalaitzaki P, Papavassiliou G, Kilikoglou V (2011) Application of 1H NMR to hydration and porosity studies of lime-pozzolan mixtures. Microporous Mesoporous Mater 139(1-3):16-24. https://doi.org/10.1016/j.micromeso.2010.10.010

Uno PJ (1998) Plastic shrinkage cracking and evaporation formulas. ACI Mater J 95(4):365-375. https://doi.org/10.14359/379

Wang D, Wang Q, Zhuang S, Yang J (2018a) Evaluation of alkali-activated blast furnace ferronickel slag as a cementitious material: reaction mechanism, engineering properties and leaching behaviors. Constr Build Mater 188:860-873. https:// doi.org/10.1016/j.conbuildmat.2018.08.182

Wang D, Wang Q, Zongxian H (2020) New insights into the early reaction of $\mathrm{NaOH}$-activated slag in the presence of CaSO4. Compos Part B Eng 198:108207. https://doi.org/10.1016/j.compositesb.2020.108207

Wang Q, Huang Z, Wang D (2018b) Influence of high-volume electric furnace nickel slag and phosphorous slag on the properties of massive concrete. J Therm Anal Calorim 131(2):873-885. https://doi.org/10.1007/s10973-017-6576-x

Wu Z, Lian H (1999) High performance concrete. China railway publishing house, Beijing

Yang T, Yao X, Zhang Z (2014) Geopolymer prepared with high-magnesium nickel slag: characterization of properties and microstructure. Constr Build Mater 59:188-194. https://doi.org/10.1016/j.conbuildmat.2014.01.038

You N, Li B, Cao R, Shi J, Chen C, Zhang Y (2019) The influence of steel slag and ferronickel slag on the properties of alkaliactivated slag mortar. Constr Build Mater 227:1 16614. https://doi.org/10.1016/j.conbuildmat.2019.07.340

Zhang A, Ge Y, Yang W, Cai X, Du Y (2019) Comparative study on the effects of nano-SiO2, nano-Fe2O3 and nano-NiO on hydration and microscopic properties of white cement. Constr Build Mater 228:116767. https://doi.org/10.1016/j. conbuildmat.2019.116767

\section{Publisher's Note}

Springer Nature remains neutral with regard to jurisdictional claims in published maps and institutional affiliations. 